\title{
CLINICAL PROFILE OF PATIENTS PRESENTING TO LOW VISION CLINIC OF A TERTIARY CENTER IN WESTERN REGION OF NEPAL
}

\author{
Thapa $\mathrm{HB}^{1}$, Gautam $\mathrm{P}^{2}$, Mahotra $\mathrm{NB}^{3}$, Bajracharya $\mathrm{K}^{4}$
}

\begin{abstract}
INTRODUCTION: Low vision is an important public health problem; however, very few low vision clinics are available to address the needs of low vision patients in most developing countries. The purpose of this study was to describe the characteristics of patients attending the low vision clinic of a tertiary care eye hospital of Western Region of Nepal.
\end{abstract}

METHODS: This was a prospective cross sectional study of all new Nepali patients seen at the low vision clinic over 2 years period. The patients were administered with clinical low vision form (a structured questionnaire) and were examined and tested with low vision devices by the attending low vision specialist. Information on the demographic and clinical characteristics of the patients was recorded.

RESULTS: A total of 214 new patients seen during the period were studied. The mean age was 19.80 years, and their ages ranged between 4 and 86 years with a male to female ratio of $2.69: 1$. Majority $(53.30 \%)$ were children ( $\leq 15 y e a r s)$, while $3.70 \%$ were elderly patients ( $\geq 65$ years).

The commonest cause of low vision was lens related like pseudophakia, aphakia $(20.60 \%) ; 18.20 \%$ had refractive error/amblyopia; $17.80 \%$ had retinitis pigmentosa; macular disorder (20\%) and retinitis pigmentosa (20\%) were the commonest cause in the adult and elderly patients, while lens related $(24.6 \%)$ and refractive error/amblyopia $(21.1 \%)$ were the commonest causes in children.

CONCLUSION: The demographic and clinical characteristics of low vision patients seen in this clinic are similar to that of patients in other developing countries, but different from those in developed countries. Elderly patients and females may be under-utilizing low vision services.

KEYWORDS: Low vision, Refractive error

1. Optometrist, Lumbini Eye Institute, Bhairahawa, Nepal

2. Ophthalmologist, Lumbini Eye Institute, Bhairahawa, Nepal

3. Assistant professor, Department of Physiology, Maharajgunj Medical Campus, Institute of Medicine, Tribhuvan University, Nepal

4. Fellow Pediatric Ophthalmology and strabismus, Lumbini Eye Institute, Bhairahawa, Nepal

\section{For Correspondence}

Mr. Hari Bahadur Thapa, B.Optom, B .Sc., M.A.

Low Vision Clinic,

Lumbini Eye Institute, Bhairahawa, Nepal

Email:haribdr2005@yahoo.com 


\section{INTRODUCTION}

A person with low vision is one who has impaired visual function despite treatment of eye disease and/ or correction of refractive error, and has reduced visual acuity in the better eye which is less than 6/18 but better than Light Perception (LP) or a visual field constriction to less than $10^{\circ}$, but who uses or is potentially able to use vision for the planning and/ or execution of a task. ${ }^{1}$ This definition of low vision excludes individuals whose visual acuity could be improved by surgical and/or medical treatment and refers to functional vision. It differs from other definitions of low vision in the literature which include all individuals presenting with impaired vision regardless of the cause, potential for treatment and the ability to use residual vision. The term "functional low vision" has been used to represent this definition in a bid to avoid the confusion with other definitions. ${ }^{2,4}$ People with functional low vision require assessment for low vision interventions, ${ }^{2}$ and such patients are the focus of this article.

Functionally, low vision is characterized by irreversible visual loss and a reduced ability to perform many daily activities, such as recognizing people in the street, reading blackboards, writing at the same speed as peers, and playing with friends. ${ }^{5}$ It is an important public health problem; ${ }^{6}$ and provision of low vision services is one of the priorities in the global initiative, VISION 2020 The Right to Sight.,

Based on figures from Mid Term Review of Vision 2020: The Right to Sight, Nepal 2011, it is estimated that approximately $2,30,000$ people of all ages have functional low vision in Nepal. The service coverage for low vision at present is less than $1 \%(1,500$ out of 230,000$)$. One half of the users of low vision services are children under 16 years of age; adolescents and adult between 16 to 39 years of age constitute $35.35 \%$ of service users. Persons over 40 years constitute just over $12 \%$ of low vision service users, in sharp contrast to the situation in developed countries where low vision services are used predominantly by older population. ${ }^{3}$ The challenge of providing low vision services for such a large population is enormous and requires proper planning and efficient use of available resources. It is, therefore, important to collect and analyze clinical data from patients with functional low vision in order to deliver appropriate low vision care.

Serious gender inequity is evident in use of low vision services, women constitute only one third of all users of low vision devices although they carry two thirds of burden of blindness. Refractive error/amblyopia is found to be major cause of low vision accounting for $26.83 \%$ of cases followed by retinal problem including retinitis pigmentosa, macular degeneration etc. Lens related conditions accounted for
$16.75 \%$ of low vision use which may signal that early detection of cataract, appropriate surgery and adequate early rehabilitation may reduce the need for low vision devices. ${ }^{3}$

This study was carried out to describe the demographic and clinical characteristics of patients presenting to the low vision clinic in western part of Nepal. We believe that the information about patients who actually attend low vision clinics would be useful for planning and delivery of effective low vision services.

\section{MATERIALSAND METHODS}

This was a prospective cross sectional study of all new Nepali patients seen at the low vision clinics of Lumbini Eye Institute (LEI) from January 2011 to December 2012. The low vision clinic was established in the hospital with the support of National Low Vision program in 2006, and services commenced in the same year. It is located in the eye clinic of the hospital with a dedicated room equipped for evaluation and testing of patients with low vision.

\section{STUDY POPULATION}

All patients presenting to the low vision clinic are seen by an optometrist who has received subspecialty training in low vision services. Low vision devices are available for purchase by clients as soon as they are prescribed. All the patients seen during the study period were administered with a structured questionnaire, and were examined and tested with different low vision devices by the attending low vision specialist. Information on the demographic and clinical characteristics of the patients was recorded. Visual Acuity (VA) was assessed with the use of $\log$ MAR charts (high contrast lea, E symbol and letter) and recorded in Snellen equivalent for distance vision and metric units $(\mathrm{M})$ for near vision.

Verbal informed consent was obtained from study participants. Ethical approval was obtained from the ethical committee of Lumbini Eye Institute. The data was analyzed with the use of Statistical Package for Social Sciences version 17 software (SPSS)

\section{RESULTS}

A total of 214 new Nepali patients presented and were seen at the low vision clinic during the study period. The mean age was 19.80 years. Their ages ranged between 4 and 86 years with standard deviation \pm 15 . Majority $(72.90 \%)$ of the patients were males with a male to female ratio of $2.69: 1$. The $6-15$ years age group had the largest proportion with $49.10 \%$ of patients; followed by the $16-39$ years age group $(36.00 \%)$. 
Figure 1: Sex distribution of low vision patients

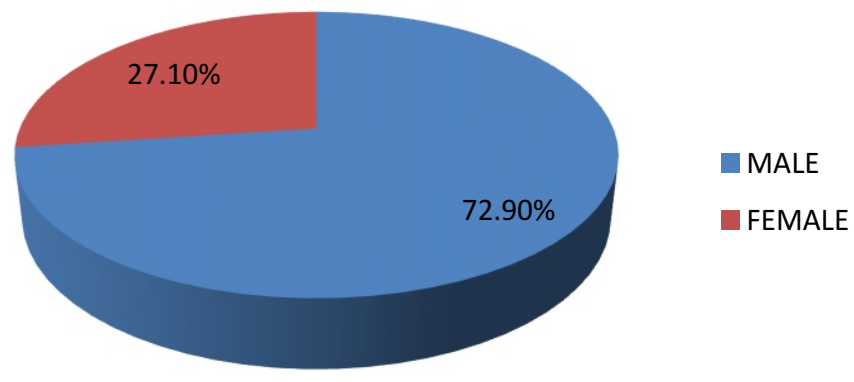

Table 1: Age and sex distribution of low vision patients

\begin{tabular}{|c|c|c|c|}
\hline Age-range & MALE & FEMALE & No. (\%) \\
\hline $0-5$ yrs & 7 & 2 & $9(4.20)$ \\
\hline $6-15 \mathrm{yrs}$ & 74 & 31 & $105(49.10)$ \\
\hline $16-39 \mathrm{yrs}$ & 55 & 22 & $77(36.00)$ \\
\hline $40-64 \mathrm{yrs}$ & 14 & 1 & $15(7.00)$ \\
\hline $65 \&$ above & 6 & 2 & $8(3.70)$ \\
\hline Total & 156 & 58 & $214(100)$ \\
\hline
\end{tabular}

$114(53.30 \%)$ patients were children (aged 15 years or less), $94(43.9 \%)$ were aged between 16 and 64 years, while 8 (3.70\%) of them were elderly patients ( 65 years and older).

Figure 2: Occupation of low vision patients

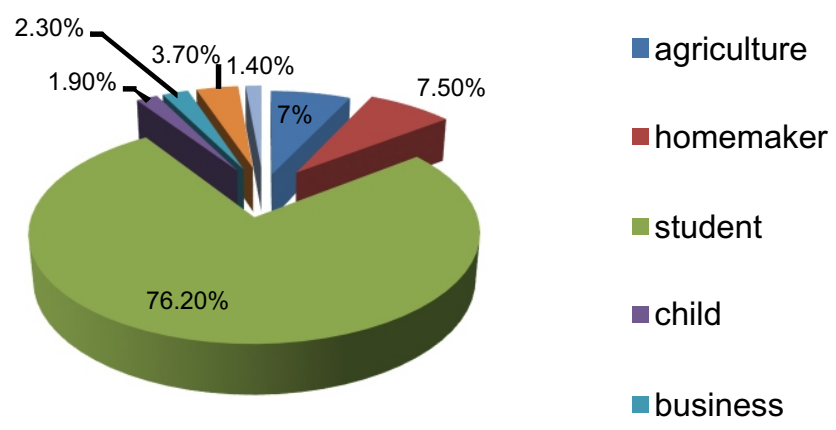

Figure 3: Referred from

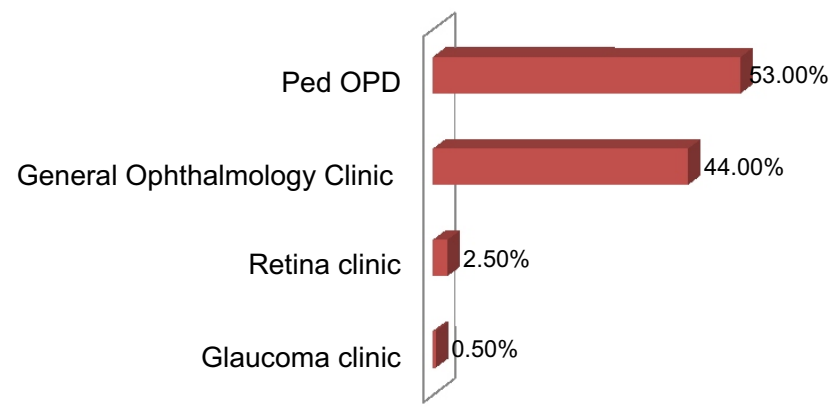

Table 2: Main presenting complaints of low vision patients

\begin{tabular}{|l|c|c|}
\hline Main compalint & Frequency(N) & Percent (\%) \\
\hline Distance vision & 45 & 21.5 \\
\hline Near vision & 47 & 22.0 \\
\hline Both distance and near vision & 116 & 54.0 \\
\hline Night blindness & 1 & 0.5 \\
\hline Restricted visual field & 5 & 2.0 \\
\hline Total & 214 & 100 \\
\hline
\end{tabular}

With regards to the main presenting complaint, $116(54.0 \%)$ patients complained of both poor distance and near vision indicating that both distance and near vision were of equal importance to them. $47(22.0 \%)$ patients said their major problem was with near vision, while $45(21.5 \%)$ reported that their main complaint was poor distance vision. One patient $(0.5 \%)$ had night blindness as the main symptom while 5 (2.0\%) patient was mainly concerned about restriction of his visual field.

Table 3: Causes of low vision

\begin{tabular}{|l|c|c|}
\hline & Frequency(N) & Percent (\%) \\
\hline Whole globe (egmicroopthalmos) & 23 & 10.70 \\
\hline Nystagmus & 12 & 5.60 \\
\hline Corneal disorder & 9 & 4.20 \\
\hline Lens related(aphakia, pseudophakia) & 44 & 20.60 \\
\hline Refractive error/amblyopia & 39 & 18.20 \\
\hline Albinism & 8 & 3.70 \\
\hline Retinitis pigmentosa & 38 & 17.8 \\
\hline Macular disorder & 33 & 15.50 \\
\hline Optic atrophy & 8 & 3.70 \\
\hline Total & 214 & 100 \\
\hline
\end{tabular}

The commonest cause of low vision was Lens related (aphakia, pseudophakia) in $44(20.60 \%)$ patients. $40.7 \%$ of the patients, the cause of low vision involved posterior segment disease.

The commonest causes of low vision among children were lens related and refractive error/amblyopia, each accounting for $20.60 \%$ and $18.20 \%$ respectively. Among the adults aged and elderly patients, the commonest cause was macular disorder and retinitis pigmentosa, each occurring in $20.0 \%$ of patients. 
Table 4: Low vision category

\begin{tabular}{|l|c|c|}
\hline Vision in best eye & Presenting & $\begin{array}{l}\text { Improved with } \\
\text { distance glasses }\end{array}$ \\
\hline$<6 / 18-6 / 60$ & $77(36 \%)$ & $82(38.20 \%)$ \\
\hline$<6 / 60-3-60$ & $52(24.30 \%)$ & $51(24 \%)$ \\
\hline$<3 / 60-1 / 60$ & $48(22.40 \%)$ & $48(22.40)$ \\
\hline$<1 / 60-$ PL & $37(17.30 \%)$ & $33(15.40 \%)$ \\
\hline Total & 214 & 214 \\
\hline
\end{tabular}

Among the patients, $38.20 \%$ could achieve a distance visual acuity of $6 / 60$ or better after receiving the correct spectacles (Table 4). $86.90 \%$ patients had improved with distance glasses. $78.50 \%$ students already had spectacles when they presented (Figure 4), but in $50 \%$ the visual acuity could be improved with a change in prescription and in total $58.40 \%$ needed a new pair.

Figure 4 : Need of distance spectacles

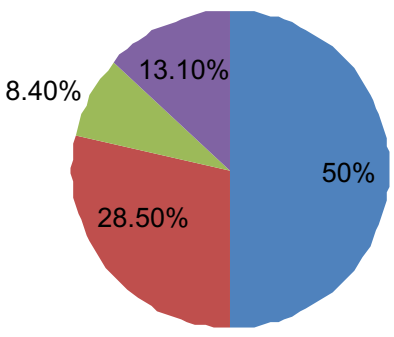

$$
\begin{aligned}
& \text { already had } \\
& \text { glasses need new } \\
& \text { pair } \\
& \text { already had } \\
& \text { glasses continue } \\
& \\
& \text { need distance } \\
& \text { glasses already } \\
& \text { had no glasses }
\end{aligned}
$$

Table 5 shows that at presentation, there were $18.70 \%$ patients having near vision $1 \mathrm{M}$ or better. After low vision assessment, $41.6 \%$ were near visual acuity $1 \mathrm{M}$ or better. $70 \%$ patients were able to read $2.5 \mathrm{M}$ or better at $10 \mathrm{~cm}$.

Table 5:Near visual acuity category

\begin{tabular}{|l|l|l|}
\hline Size & Presenting & Improved \\
\hline $1 \mathrm{M}$ or better $@ 10 \mathrm{~cm}$ or more & $40(18.70 \%)$ & $89(41.60 \%)$ \\
\hline $1.25 \mathrm{M}-2.5 \mathrm{M} @ 10 \mathrm{~cm}$ or more & $92(43 \%)$ & $60(28 \%)$ \\
\hline $3 \mathrm{M}-4 \mathrm{M} @ 10 \mathrm{~cm}$ or more & $21(9.8 \%)$ & $18(8.40 \%)$ \\
\hline$>4 \mathrm{M}$ & $61(28.50 \%)$ & $47(22 \%)$ \\
\hline Total & 214 & 214 \\
\hline
\end{tabular}

\section{DISCUSSION}

This study has presented data from a population of low vision clinic patients. A major advantage of low vision clinic studies when compared with population surveys, blind school studies or blind register studies is that they provide more reliable and usually detailed ophthalmic information about people with low vision. ${ }^{11,12}$ The information obtained from such studies can be very useful for planning low vision services, active care and rehabilitation. ${ }^{6}$

The age distribution of our patients is different from previous reports from developed countries but is similar to those from other developing countries. Although the incidence of low vision has been reported to increase with age, ${ }^{12}$ in our study, a significant proportion (84\%) of patients was below 30 years and majority (93\%) were below 50 years of age, while only $4 \%$ were aged 60 years and above. This depiction of a younger population is similar to findings from Malaysia, ${ }^{14}$ Korea $^{6}$ and India $^{16}$ in which the proportion of patients aged below 50 years were $74 \%, 69 \%$ and $68 \%$ respectively. In these developing countries, the proportion of low vision patients aged 60 years and above ranged between $16 \%$ and $26 \%$.

On the other hand, in studies from developed countries, Leat and Rumney ${ }^{17}$ (United Kingdom) found $77 \%$ of their patients to be aged 60 years and above; Elliot et al. ${ }^{11}$ (Canada) reported that $66 \%$ of patients were 70 years or older; while in Australia, Wolffsohn and Cochrane ${ }^{12}$ observed that $87 \%$ of patients were aged 60 years and above. This difference in the pattern of the age distribution may be a reflection of the older general populations in developed countries ${ }^{11,14}$ and low life expectancy in developing countries. ${ }^{16}$

The relatively high male to female ratio in our study is similar to that of other studies conducted in developing countries as follows: Korea- 1.8: $1^{6}$, Malaysia- 2.2:1 ${ }^{14}$ and India- 2.6:1. ${ }^{16}$ It is, however, different from the pattern in developed countries where more females were found to present for low vision services. ${ }^{11-13}$ This probably demonstrates the reduced access and utilization of eye care services by females in developing countries. $^{9,10}$

Majority of our patients considered their problems with near and distance vision to be of equal importance. However, elderly patients were more likely to deem near vision as being their major problem; while children had a tendency to judge distance vision as more important. This observation perhaps portrays the additional effect of presbyopia on low vision in the elderly, although it may also signify that the elderly have a greater likelihood of central visual loss from macular disease. Posterior segment disease accounted for the majority of causes of low vision in this study. This correlates with findings of most low vision clinic studies. ${ }^{6,11,12,14-17}$

We found lens related like pseudophakia and aphakia to be the commonest cause of low vision in this study. Similarly, in Mid Term Review of Vision 2020, 2011, it was the third most common cause of low vision, accounting for $16.75 \%$ of subjects with low vision. 
Similarly to the report by Richard ${ }^{8}$ in which cataract was the most common cause of low vision, cataract was common in the study because most cases of pediatric cataract were managed in the pediatric department and referred to the low vision clinic if needed. The pediatric cataract Initiative program was conducted in the hospital during that period focusing on active follow up of the post operative children after cataract surgery. That helped us to get more children with lens related low vision.

Retinitis pigmentosa has been found to be the third major cause of low vision in our study. Khan found it to be the commonest cause in a population of 410 low vision patients in India. ${ }^{16}$ While Mohidin and Yusoff observed it to be the second commonest cause in a Malaysian low vision clinic. ${ }^{14}$

\section{CONCLUSIONS}

It shows that the clinical characteristics of low vision patients in our setting are similar to that of patients in other developing countries, but different from those in developed countries. In addition, elderly patients and females may be under-utilising low vision services. We recommend that eye care practitioners including ophthalmologists, optometrists, ophthalmic assistants and general medical practitioners in Nepal should be encouraged to be more aware about identifying patients with low vision, especially females and the elderly and promptly referring such patients for low vision assessment.

\section{REFERENCES}

1. World Health Organisation. The management of low vision of childhood. Bangkok: WHO/PBL/93.27; 1993.

2. Gilbert CE, Ellwein LB. Prevalence and causes of functional low vision in school-age children: results from standardized population surveys in Asia, Africa, and Latin America. Invest Ophthalmol Vis Sci. 2008;49(3):87781. http://dx.doi.org/ 10.1167/iovs.07-0973 PMid:18326706

3. Mid Term Review of Vision 2020: The Right to Sight, Nepal, 2011 :Ministry of Health \&Population, Government of Nepal, Ramshahapath,Kathmandu,2011.

4. Shah SP, Minto H, Jadoon MZ, Bourne RR, Dineen B, Gilbert $C E$, Khan MD. Prevalence and causes of functional low vision and implications for services: the Pakistan National Blindness and Visual Impairment Survey. Invest Ophthalmol Vis Sci. 2008;49(3):88793. http://dx.doi.org/10.1167/iovs.07-0646

5. Van Dijk K. Providing care for children with low vision. Community Eye Health.2007;20(62):2425.PMid:17612692 PMCid: PMC1906921
6. Kim JH, Joo KS, Moon NJ. Characteristics of 681 low vision patients in Korea. J Korean Med Sci.2010;25(8):121722. http:// dx.doi.org /10.3346/jkms.2010.25.8.1217PMid:20676336 PMCid:PMC2908794

7. World Health Organisation. Global initiative for the elimination of avoidableblindness.WHO/PBL/97.61_Rev.1, Geneva; 1997.

8. Richard AI. Causes of blindness and low vision in Bayelsa State, Nigeria: a clinic based study. Nig Q J Hosp Med. 2010;20(3) :1258. PMid:21033320

9. Fletcher AE, Donoghue M, Devavaram J, Thulasiraj RD, Scott $S$, Abdalla M, Shanmugham AK, Murugan PB. Low uptake of eye services in rural India: a challenge for programs of blindness prevention. Arch Ophthalmol. 1999;117(10):13939. http://dx.doi.org/10.1001/archopht.117.10.1393 PMid: 10532449

10. Snellingen T, Shrestha BR, Gharti MP, Shrestha JK, Upadhyay $M P$, Pokhrel RP. Socioeconomic barriers to cataract surgery in Nepal: the South Asian cataract management study. $\mathrm{Br} J$ Ophthalmol. 1998;82(12):14248. http://dx.doi.org/10.1136/ bjo. 82.12.1424 PMid:9930276 PMCid:PMC1722440

11. Elliott DB, Trukolo-Ilic M, Strong JG, Pace R, Plotkin A, Bevers P. Demographic characteristics of the vision-disabled elderly. Invest Ophthalmol Vis Sci. 1997;38(12):256675. PMid:9375576

12. Wolffsohn JS, Cochrane AL. The changing face of the visually impaired: the Kooyong low vision clinic's past, present, and future. Optom Vis Sci. 1999;76(11):74754 http://dx.doi.org/ 10.1097/00006324-199911000-00023

13. Crossland MD, Silver JH. Thirty years in an urban low vision clinic: changes in prescribing habits of low vision practitioner . Optom Vis Sci. 2005;82(7):61722 http://dx.doi.org /10.1097/ 01.opx.0000171336.40273.3f

14. Mohidin N, Yusoff S. Profile of a low vision clinic population. ClinExpOptom. 1998;81(5):198202.http://dx.doi.org/10.1111/ j.1444-0938.1998.tb06735.xPMid:12482319

15. Paudel P, Khadka J, Sharma AK. Profile of a low vision population. IntCongr Ser.2005;1282:2526. http://dx.doi.org /10.1016/j.ics.2005.05.191

16. Khan $S A$. A retrospective study of low-vision cases in an Indian tertiary eye-care hospital. Indian $J$ Ophthalmol. 2000;48(3):2017. PMid:11217251

17. Leat SJ, Rumney NJ. The experience of a university-based low vision clinic. Ophthalmic Physiol Opt. 1990;10(1):815. http://dx.doi.org/10.1111/j.1475-1313.1990.tb01098.x 